\title{
CIBERESPACIO, EDUCACIÓN Y CULTURA ESCRITA ALGUNAS REFLEXIONES SOBRE EL LIBRO DE PIERRE LÉVY Cibercultura. LA CULTURA DE LA SOCIEDAD DIGITAL
}

\author{
Giovanna Carvajal Barrios ${ }^{1}$ \\ Profesora \\ Escuela de Comunicación Social \\ Universidad del Valle \\ giovanacarv@hotmail.com
}

\section{Resumen:}

El presente artículo se propone, en primer lugar, derivar de la lectura del libro de Pierre Lévy Cibercultura. La cultura de la sociedad digital una caracterización preliminar de la cibercultura y del ciberespacio, prestando particular atención a los conceptos que les son propios y a las implicaciones que dichos conceptos tienen en las formas de concebir (definir, caracterizar) y realizar las prácticas de lectura y escritura. En segundo lugar, discutir los planteamientos de Lévy acerca de las implicaciones que tiene la cibercultura para la sociedad, específicamente en lo relacionado con la educación y de manera más específica con las prácticas de lectura y escritura. Tales objetivos están articulados a la formulación de la pregunta de investigación en el proyecto de tesis doctoral denominado "La cultura escrita en el ciberespacio: ¿Nuevos conceptos, nuevas prácticas?”, inscrito en el Doctorado en Ciencias de la Educación, Área Pensamiento Educativo y Comunicación, RUDECOLOMBIA, Universidad Tecnológica de Pereira.

\section{Palabras Clave:}

ciberespacio, cibercultura, lectura, escritura, cultura escrita. 


\begin{abstract}
:
This article attempts to, at first place, make of the Pierre Lévy's book Cibercultura. La cultura de la sociedad digital a preliminary characterization of the cyberculture and cyberspace, giving a particular attention to its concepts and to the implications of those concepts in the ways of conceive, define, characterize and perform the reading and writing practices. At second place, this article attempts to discuss about the ideas of Lévy on the implications of cyberculture in the society, specifically in the space of education and more specifically in the reading and writing practices. Those purposes are articulated to the formulation of the research-question in the doctoral thesis project named "La cultura escrita en el ciberespacio: ¿nuevos conceptos, nuevas prácticas?", of the Doctorado en Ciencias de la Educación, Área Pensamiento Educativo y Comunicación, RUDECOLOMBIA, Universidad Tecnológica de Pereira.
\end{abstract}

Keywords: cyberspace, cyberculture, reading, writing, writing culture.

Una tecnología de comunicación surge en un contexto donde confluyen diferentes fenómenos sociales y culturales. La tecnología ingresa a un conjunto de procesos sociales preexistentes, donde hay relaciones de poder, conflictos de intereses, expectativas distintas, modos de acceso discriminado y grados de apropiación heterogéneos. Como consecuencia de ello, la tecnología no tiene para todos los individuos y grupos un mismo significado, ni da lugar a lecturas idénticas sobre los fenómenos que ella acarrea. Las tecnologías digitales no son la excepción. Pierre Lévy, en su libro Cibercultura. La cultura de la sociedad digital, aborda el significado que ha tenido el advenimiento de la informática y del ciberespacio, sus implicaciones culturales, los retos sociales que plantea y las posibilidades que despliega en el inicio del siglo XXI.

Un análisis como el que Lévy se propone hacer en su libro trae consigo varias dificultades. En primer lugar, contrario a lo que sucede con la escritura alfabética o con los medios de comunicación de masas (el cine, la radio, la televisión), la invención de las tecnologías digitales es un hecho relativamente reciente y los cambios que se están dando en este ámbito se producen a una velocidad exorbitante. En segundo lugar, el uso de las redes digitales despierta reacciones disímiles, que van del temor a la fascinación. No estamos preparados, nos lo dice Pierre Lévy, para enfrentar de un modo creativo e innovador, a partir de conceptualizaciones que estén acorde con los fenómenos en curso, tanto las dificultades como las oportunidades que se derivan del ciberespacio como tecnología de comunicación interactiva.

El presente artículo se propone, en primer lugar, derivar de la lectura del libro de Pierre Lévy una caracterización preliminar de la cibercultura y el ciberespacio, prestando particular atención a los conceptos que le son propios y a las implicaciones que dichos conceptos tienen en las formas de concebir (definir, caracterizar) y realizar las prácticas de lectura y escritura. En segundo lugar, discutir los planteamientos de Lévy acerca de las implicaciones que tiene la cibercultura para la sociedad, específicamente en lo relacionado con la educación y de manera más específica con las prácticas de lectura y escritura. Todo ello, pensando de manera particular en el contexto de la nación colombiana ${ }^{2}$. 


\section{Los retos de lo irreversible: la perspectiva teórica de Pierre Lévy}

Piere Lévy asume una perspectiva no determinista acerca de la presencia de las tecnologías informáticas y del ciberespacio. Para él, la técnica no determina, sino que condiciona, es decir, abre ciertas posibilidades y opciones culturales o sociales que no se podrían considerar sin su presencia. Ahora bien, no todas las posibilidades abiertas por el ciberespacio son escogidas por todos, ni se integran de la misma manera a las realidades sociales y culturales de las comunidades de usuarios (p. 10) ${ }^{3}$.

Para el autor, el trabajo teórico sobre las tecnologías informáticas no debe estar orientado a "medir impactos", sino a descubrir "irreversibilidades". Una vez asumimos que hay ciertos procesos que resultarán inevitables - por lo menos para el conjunto mayoritario de la sociedad- debemos pensar en la manera de enfrentarlos, decidir el uso que daremos a los nuevos recursos y sacar de ellos el máximo provecho (11).

\section{El ciberespacio y la cibercultura: hacia una caracterización inicial}

El ciberespacio es, desde la perspectiva de Pierre Levy, espacio de comunicación, canal de información ligado a la digitalización y soporte de memoria. En la siguiente definición dada por el autor convergen los rasgos característicos del ciberespacio:

“Defino el 'ciberespacio' como el espacio de comunicación abierto por la interconexión mundial de los ordenadores y de las memorias informáticas. Esta definición incluye el conjunto de sistemas de comunicación electrónicos (comprendiendo el conjunto de las redes hertzianas y telefónicas clásicas) en la medida en que transportan informaciones provenientes de fuentes digitales o destinadas a la digitalización. Insisto sobre la codificación digital pues condiciona el carácter plástico, fluido, finamente calculable y tratable en tiempo real, hipertextual, interactivo y, para decirlo todo, virtual, de la información que es, me parece, la marca distintiva del ciberespacio. Este nuevo medio tiene por vocación poner en sinergia y en interfaz todos los dispositivos de creación de información, de grabación, de comunicación y de simulación. La perspectiva de la digitalización general de las informaciones y de los mensajes hará probablemente del ciberespacio el principal canal de comunicación y el primer soporte de memoria de la humanidad a lo largo del siglo XXI" (71).

Los principales modos de comunicación y de interacción que permite el ciberespacio son : el acceso a distancia a los diversos recursos de un ordenador (potencia de cálculo en tiempo real, acceso al contenido de bases de datos o a la memoria de un ordenador lejano, transferencia de ficheros o descarga) (72); las funciones de mensajería (correo electrónico); las conferencias electrónicas (dispositivo "que permite a grupos de personas discutir juntos sobre temas particulares") (77); la comunicación a través de un mundo virtual compartido (“... mantener una relación sensorio motriz con el contenido de una memoria informática”, en función o en el contexto de la interacción con otros individuos en un dispositivo del tipo todos-con todos) (78). 
Dispositivos informacionales y comunicacionales inaugurados por el ciberespacio ${ }^{4}$

El mundo virtual y la información en flujo son los dos dispositivos informacionales inaugurados por el ciberespacio. El mundo virtual dispone las informaciones en un espacio continuo - y no en la red- y ello en función de la posición del explorador o de su representante en el mundo (principio de inmersión). “(...) La información en flujo designa los datos continuamente cambiantes y dispersados entre memorias y canales interconectados que pueden ser recorridos, filtrados y presentados al cibernauta según sus instrucciones, gracias a agentes de programas, sistemas de cartografía dinámica de datos u otras ayudas a la navegación" (48).

En cuanto al dispositivo comunicacional, "el ciberespacio establece un dispositivo comunicacional original [todos-todos] que permite a comunidades constituir progresivamente y de manera cooperativa un contexto común”, desarrollar una comunicación ininterrumpida y como consecuencia de ello generar una memoria colectiva "que emerge de la comunicación entre los participantes" (49).

Una vez presentada de manera sintética la definición del ciberespacio, podemos abordar sus rasgos característicos:

2.1 Rapidez de los cambios relacionados con la cibercultura:

causa y consecuencia

La velocidad como rasgo característico de la cibercultura se presenta en un doble sentido: velocidad en los procesos llevados a cabo por la tecnología, y rapidez en la generación de cambios al interior de la sociedad.

“(...) el lenguaje digital, fluido, en constante mutación [está] desprovisto de esencia estable. (...) la rapidez de transformación es por sí misma una constante - paradójica- de la cibercultura. Explica en parte la sensación de impacto, de exterioridad, de extrañeza que nos invade cuando intentamos aprehender el movimiento contemporáneo de las técnicas. (...) La aceleración es tan fuerte y tan general que incluso los que consideran estar más 'a la última' están, en diversos grados, desbordados por el cambio" (12).

En el ámbito educativo, donde indudablemente la cibercultura está generando transformaciones significativas, se observa una tendencia doble a la obsolescencia precoz: la de los artefactos y la de los conocimientos. La rapidez de los cambios técnicos contribuye a alimentar el "sentimiento de extrañeza", el cual está asociado a la imagen difusa y opaca que tienen muchos usuarios de los procesos que están involucrados en el ciberespacio. Frente a este movimiento de cambio permanente, surge la inteligencia colectiva, definida por Lévy como uno de los principales motores de la cibercultura" (13). 
2.2 Interconexión, comunidades virtuales e inteligencia colectiva: tres principios que han orientado el crecimiento del ciberespacio.

- La interconexión es la condición sine qua non del ciberespacio. Para la cibercultura la conexión es un bien en sí. "Unido al crecimiento de las capacidades de transmisión, la tendencia a la interconexión provoca una mutación en la física de la comunicación: se pasa de las nociones de canal y red a una sensación de espacio englobante" (100). Pero, más allá del fenómeno físico de la comunicación, "la interconexión constituye la humanidad en continuo sin frontera, atraviesa un medio de información oceánico, sumerge los seres y las cosas en el mismo baño de comunicación interactivo. La interconexión teje un universal por contacto” (100). Universal que, para Pierre Lévy, constituye uno de los cambios sin precedentes que trae consigo el ciberespacio.

- Las comunidades virtuales se desarrollan gracias a la interconexión. "Una comunidad virtual se construye sobre afinidades de intereses, de conocimientos, compartiendo proyectos, en un proceso de cooperación o de intercambio, y esto independientemente de las proximidades geográficas y de las pertenencias institucionales" (100).

Pierre Lévy rebate una serie de preconceptos que existen con respecto a las comunidades virtuales: Contrario a lo que muchos suponen, en las relaciones en línea están presentes las emociones, así como la responsabilidad individual y el juicio de la opinión pública. Los rasgos de la personalidad de los participantes se infieren de su forma de expresarse, de las posturas adoptadas, de los intereses manifiestos, de sus competencias y de su estilo de escritura. Por ello, tanto el conflicto como la posibilidad de tejer lazos de amistad están presentes en las relaciones que se dan en las comunidades virtuales. Aún así, la comunicación a través de las redes informáticas no reemplaza los encuentros físicos. En las comunidades virtuales opera una ética que -pese a no estar escrita- regula las relaciones y debe ser compartida, so pena de ser excluido (100-101).

- La inteligencia colectiva constituye la finalidad última, la "perspectiva espiritual" de la cibercultura. En palabras de Lévy, "el mejor uso que se puede hacer del ciberespacio es el de poner en sinergia los conocimientos, las imaginaciones, las energías espirituales de aquellos que se conectan a él" (104).

En el numeral siguiente se desarrolla el tópico de la inteligencia colectiva, dada la importancia que tiene en la caracterización del ciberespacio y la cibercultura. 


\subsection{Inteligencia colectiva}

Si el ideal que movilizaba el desarrollo de la informática era la inteligencia artificial (lograr que una máquina sea tan inteligente o incluso más inteligente que el hombre), hoy en día, el ideal lo constituye la inteligencia colectiva. Ésta es definida por Pierre Lévy como "la valoración, la utilización óptima y la sinergia de las capacidades, las imaginaciones y las energías intelectuales, sea cual sea su diversidad cualitativa y su ubicación”. Lograr ello implica necesariamente "un uso compartido de la memoria, la imaginación y la experiencia, la práctica vulgar del intercambio de conocimientos y la introducción de nuevas formas de organización y coordinación flexibles y en tiempo real” (Lévy, 1999:9).

El desarrollo de los procesos de inteligencia colectiva: conlleva al cuestionamiento de diversos poderes; permite una mejor apropiación de los cambios técnicos por parte de los individuos y los grupos; ayuda a contrarrestar los "efectos excluyentes o humanamente destructores" que trae consigo "la aceleración del movimiento tecnosocial" (13).

La inteligencia colectiva es, en un primer sentido, el resultado del ciberespacio y, en un segundo sentido, el motor éste. En el primer sentido, el ciberespacio facilita un entorno propicio (accesibilidad e interconectividad que permite interactividad en tiempo real) para el desarrollo de la inteligencia colectiva (14). Sin embargo, dicho desarrollo puede ser frenado cuando existe la tendencia a defender un determinado poder y a favorecer la rigidez institucional, o cuando existen modos de inercia de la mentalidad y de la cultura, en cuyo caso se daría lugar "a un uso social de las nuevas tecnologías mucho menos positivo según criterios humanistas" (1999:9). Por ello no puede esperarse que la cibercultura garantice en sí misma la presencia de formas de inteligencia colectiva.

En el segundo sentido, una vez "algunos procesos de inteligencia colectiva se desarrollan efectivamente gracias al ciberespacio, tienen notablemente por efecto acelerar de nuevo el ritmo del cambio tecnosocial, lo que hace tanto o más necesaria la participación activa en la cibercultura si uno no quiere quedarse atrás, y tiende a excluir de manera aún más radical a aquellos que no han entrado en el ciclo positivo del cambio, de su comprensión y de su apropiación” (15). En síntesis, "por su aspecto participativo, socializante, abierto y emancipador, la inteligencia colectiva propuesta por la cibercultura constituye uno de los mejores remedios contra el ritmo desestabilizador, a veces excluyente, de la mutación técnica. Pero, con el mismo movimiento, la inteligencia colectiva trabaja activamente en la aceleración de esa mutación" (15). 


\subsection{Tendencia a la virtualización}

La virtualidad es, para Pierre Lévy, "el rasgo distintivo de la nueva figura de la información" (32). De las tres acepciones que tiene la palabra virtual (el sentido filosófico; el sentido técnico, ligado a la informática; y el sentido corriente, que opone lo virtual a lo real), Lévy adopta el sentido filosófico, por cuanto es el que le permitirá plantear que lo virtual es una dimensión - muy importante, además- de la realidad.

Según la acepción filosófica, "es virtual lo que no existe más que en potencia y no en acto, el campo de fuerzas y problemas que tienden a resolverse en una actualización. Lo virtual está más allá de la concreción efectiva o formal (el árbol está virtualmente presente en la semilla)". Teniendo en cuenta lo anterior, desde el rigor de la filosofía, "lo virtual no se opone a lo real sino a lo actual: virtualidad y actualidad son solamente dos modos diferentes de la realidad. Si en la esencia del grano está producir un árbol, la virtualidad del árbol es real (sin ser aún actual) (...) aunque no se le pueda fijar en ninguna coordenada espaciotemporal, lo virtual es sin embargo real” (33).

Para Lévy, la cibercultura está ligada a lo virtual de manera directa e indirecta:

"Directamente la digitalización de la información puede ser asimilada a una virtualización", pues los códigos informáticos, aunque son invisibles se pueden transferir de un nudo a otro de la red y son "casi independientes de las coordenadas espaciotemporales determinadas. En el seno de las redes digitales, la información está como es evidente físicamente situada en alguna parte, en un soporte dado, pero está también virtualmente presente en cada punto de la red donde se la pedirá". Además, "la información digital (traducida en dígitos 0 y 1 ) pude ser también calificada de virtual en la medida en que es inaccesible como tal al ser humano. No se puede conocer directamente más que su actualización por medio de un modo de exposición u otro" (34).

"Indirectamente, el desarrollo de las redes digitales interactivas favorece otros movimientos de digitalización distintos de aquellos de la información propiamente dicha. Así, la comunicación prosigue con lo digital un movimiento de virtualización iniciado desde hace tiempo por medio de técnicas más antiguas, tales como la escritura, como la grabación del sonido y de la imagen, la radio, la televisión y el teléfono. El ciberespacio anima un estilo de relación casi independiente de los lugares geográficos (telecomunicación, telepresencia) y de la coincidencia de los tiempos (comunicación asincrónica). Sólo las particularidades técnicas del ciberespacio permiten a los miembros de un grupo humano (que puede ser tan numeroso como se crea) coordinarse, cooperar, alimentar y consultar una memoria común, y esto casi en tiempo real a pesar de la distribución geográfica y las diferencias horarias" (35).

En síntesis, el ciberespacio tiene un carácter virtualizador y desterritorializador, expresado en la "ubicuidad de la información, [los] documentos interactivos interconectados, [la] telecomunicación recíproca y asíncrona de grupo y entre grupos" (36). 
2.5 Lo universal sin totalidad: proyecto cultural del

ciberespacio

El carácter universal del ciberespacio está dado por la posibilidad de interconectividad y digitalización/virtualización. El acceso a la red, sin restricciones, posibilita que los usuarios del ciberespacio aporten -sin censura alguna- a la información que circula en él y se alimenten -sin restricciones- de las contribuciones de los demás.

El tipo de universalidad que posibilita el ciberespacio se diferencia del que fue instaurado por la escritura y del que -tributario del anterior- es implementado actualmente por los medios de comunicación. Se trata de una forma de lo universal que se basa en la unificación del sentido (cierre semántico) y que hace que se identifiquen como uno solo universal y totalidad. A esta forma de lo universal corresponde la definición del sentido de lo escrito que -por fuera del contexto de la enunciación (que sí posibilitaba la oralidad)-, debía ser precisado por el autor y descrifrado por el lector, en correspondencia con unos modelos legitimados socialmente ${ }^{5}$. Tanto la ciencia como las religiones "universales" operan ese tipo de universal totalizante, pues ambas están basadas en textos escritos. "En lo universal fundado por la escritura lo que debe mantenerse inmutable por interpretaciones, traducciones, traslaciones, difusiones, conservaciones, es el sentido. La significación del mensaje debe ser la misma aquí y allá, tanto hoy como ayer. Este universal es indisociable de una intención de cierre semántico. Su esfuerzo de totalización lucha contra la pluralidad abierta de los contextos atravesados por los mensajes, contra la diversidad de las comunidades que los hacen circular. De la invención de la escritura se siguen las exigencias muy especiales de la descontextualización de los discursos. A partir de este acontecimiento, el dominio englobante de la significación, la pretensión del 'todo', la tentativa de instaurar en cada lugar el mismo sentido (o, para la ciencia, la misma exactitud) están para nosotros asociados a lo universal" (88). En contraste con la anterior perspectiva, para Lévy lo universal debe entenderse como "una especie de aquí y ahora virtual de la humanidad". Por eso no debe confundirse con 'totalidad', pues la 'totalización' en las formas culturales derivadas de la escritura “opera sobre la identidad de la significación” (un significado único para todos, siempre y en cualquier lugar). "Aunque lo universal y la totalización (la totalización, es decir, el cierre semántico, la unidad de la razón, la reducción al común denominador, etc.) hayan estado unidos desde siempre, su conjunción encubre fuertes tensiones, dolorosas contradicciones que la nueva ecología de los medios de comunicación polarizada por el ciberespacio quizás permita resolver. Sin embargo, subrayémoslo, esta resolución no está de ninguna manera garantizada ni es automática” (90). 
Lo universal sin totalidad, inaugurado por el ciberespacio (92-93):

- Es resultado de la interconexión generalizada.

- No está articulado al cierre semántico exigido por la descontextualización.

- "No totaliza a través del sentido, sino que re-enlaza por el contacto, por la interacción general”.

- Desliga universalidad y totalidad.

- Se experimenta por inmersión y no por la identidad de sentido.

- Permite el "acceso a un goce de lo mundial, a la inteligencia colectiva en acto de la especie”.

- "Nos hace participar más intensamente en la humanidad viva, [pues da lugar a] la multiplicación de las singularidades".

- No se entiende como una "dilatación de lo local" ni como "la exportación forzada de los productos de una cultura particular".

- "Expresa la diversidad de lo humano".

En conclusión, lo universal "es la presencia (virtual) de la humanidad en ella misma". En lo que respecta a la totalidad, puede definirse "como la reunión estabilizada del sentido de una pluralidad (discurso, situación, conjunto de acontecimientos, sistema, etc.)”. No importa si dicha identidad global se cierre "en el horizonte de un proceso complejo, [resulte] del desequilibrio dinámico de la vida, [emerja] de las oscilaciones y contradicciones del pensamiento, (...) la totalidad permanece aún bajo el horizonte del mismo". Por el contrario, la cibercultura permite "instaurar la presencia virtual propia de la humanidad (lo universal) de otra manera que a través de la identidad del sentido (la totalidad)" (94). Cuanto más universal es el ciberespacio (extendido, interconectado, interactivo), menos totalizador es" (93).

2.6 La educación y el ciberespacio: nuevas posibilidades, nuevos retos ${ }^{6}$

La reflexión sobre el futuro de la educación y de la capacitación en la cibercultura implica necesariamente plantearse los cambios que se están produciendo en nuestra relación con el conocimiento. Según lo planteado por Lévy, dichos cambios se manifiestan inicialmente en tres dimensiones:

- El flujo del saber. El saber y el saber hacer se renuevan de manera veloz. En otras palabras, hay una tendencia a la obsolescencia precoz, que no se limita al artefacto tecnológico como tal, sino a la vigencia de los conocimientos.

- El trabajo como transacción de conocimientos. La naturaleza del trabajo se encuentra ligada a la transacción de conocimientos: "cada vez más, trabajar es aprender, transmitir y producir conocimientos" (2).

- Las nuevas tecnologías de la inteligencia individual y colectiva. "El ciberespacio constituye un soporte para las tecnologías intelectuales que amplifican, exteriorizan y modifican numerosas funciones cognitivas del ser humano: la memoria (...), la imaginación (...), la percepción (...), los razonamientos (...). Estas tecnologías intelectuales favorecen nuevas formas de acceso a la información (...) y nuevos estilos de razonamiento y conocimiento" (2). 
Para Lévy, estas tres dimensiones hacen que cambie el enfoque de la educación y la capacitación, en dos sentidos: (a) resulta difícil definir y planificar con exactitud qué se debe aprender; (b) tanto la definición como la adquisición de competencias se asumen como un proceso individual para cada sujeto.

Como consecuencia de ello, el autor propone cambiar el modelo empleado para representar el espacio del conocimiento: pasar de la representación tradicional (el conocimiento adquirido de manera lineal, a través de etapas o escalones; el ascenso en una pirámide, previo cumplimiento de prerrequisitos) a "una imagen de espacios de conocimientos emergentes y en flujo, abiertos, continuos, no lineares, que se organizan según objetivos o contextos (...)” (3).

Lévy plantea que las implicaciones del ciberespacio para la educación se manifiestan en tres niveles:

a) Nuevas formas de acceso a la información

- El ciberespacio proporciona acceso en tiempo real a los distintos recursos provenientes de todos los lugares del planeta. Los estudiantes pueden participar en conferencias electrónicas desterritorializadas.

- La red favorece la accesibilidad, en un doble sentido: para la producción y para el consumo. Esto conduce paradójicamente- a que el conocimiento presente en el ciberespacio sea no cuantificable e inabarcable.

- Los conocimientos emergen constantemente, lo cual hace posible y necesaria la permanente actualización de los mismos.

- Es posible acceder sin restricciones y de forma directa a la información de última hora y a los discursos de los especialistas.

b) Nuevos estilos de razonamiento y conocimiento:

- El paradigma deja de ser "el curso" y pasa a ser "la navegación".

- En el ciberespacio se accede al conocimiento de manera a la vez masiva y personalizada.

- El ciberespacio posibilita el aprendizaje cooperativo. Éste constituye para Lévy la tendencia más prometedora en lo que concierne a los nuevos modelos de adquisición de conocimientos.

- El ciberespacio promueve la inteligencia colectiva y se alimenta de ella. 
c) Formas de organización social

- Posibilidad de una comunicación directa e interactiva.

- La interconexión favorece los procesos de inteligencia colectiva en las comunidades virtuales.

- En el ciberespacio es posible compartir los recursos materiales e informáticos sin importar el tiempo y la distancia.

2.7 La educación más allá del ciberespacio: algunas preguntas

A continuación me detendré en algunas de las implicaciones derivadas de la presencia del ciberespacio en la educación (y de la educación en el ciberespacio) para formular algunas preguntas que considero pertinentes.

a) En lugar de un camino unidireccional, de una secuencia predeterminada, el usuario del ciberespacio no sólo puede, sino que debe crear su propia ruta. Esto le exige tener criterios para seleccionar entre el cúmulo de informaciones disponibles, discriminar entre diversas perspectivas y puntos de vista, tomar decisiones para construir su propia visión sobre el tema...

¿No implica ello la necesidad de que los lectores del ciberespacio - entre ellos nuestros estudiantes- tengan un grado mínimo de adscripción a la cultura escrita ${ }^{7}$ y que estén en capacidad de hacer una lectura en doble vía, es decir, desde la perspectiva de la organización del texto dada por su autor y desde la perspectiva de la cognición social del lector? (Ulloa y Carvajal, 2006, 2011).

b) Ante el carácter "profuso, abierto, radicalmente heterogéneo y no totalizable" del ciberespacio (Lévy, 1999:5), resulta pertinente preguntarnos ¿qué tipos de conocimientos se requieren para apropiarse de los conocimientos que nos pone a la mano -sólo con un click- el ciberespacio? ¿Qué debemos "saber hacer” además de dominar las "técnicas de navegación"?

c) Pierre Lévy aborda las transformaciones en los tipos de relación con el conocimiento, con el fin de identificar la "ruptura cognitiva" que ha traído consigo la cibercultura. Para ello distingue cuatro tipos de conocimientos, cada uno de los cuales corresponde a una ecología cognitiva en la que distintos actores se ubican “en el centro de los procesos de acumulación y explotación del saber" (1999:7).

El primer tipo de conocimiento corresponde a las sociedades anteriores a la escritura. En ese contexto, "la comunidad viva era la que encarnaba el saber práctico, mítico y ritual". (7). El segundo tipo de conocimiento surge con la llegada de la escritura. En ese momento, el libro constituye el vehículo del saber: "El libro, único, infinitamente interpretable, trascendente, lo abarcaba supuestamente todo (...) El intérprete, pues, era quien dominaba el conocimiento" (7). El tercer tipo de conocimiento aparece con la invención de la imprenta, a partir de la cual el conocimiento está asociado a la figura del sabio o científico: "El portador del saber ya no es el libro, sino la biblioteca (...) El conocimiento se estructura en una red de referencias, que quizás haya buscado siempre el hipertexto. 
El concepto, la abstracción o el sistema sirven para condensar la memoria y garantizar un dominio intelectual que la inflación de conocimientos está poniendo en peligro” (8). El cuarto tipo de conocimiento tiene como preludio la desterritorialización de la biblioteca: "Por medio de una especie de regreso en espiral a la oralidad original, el vehículo del saber podría volver a ser el colectivo humano vivo, en lugar de los soportes separados utilizados por intérpretes o sabios. Sólo que esta vez, a diferencia de la oralidad arcaica, el portador directo del saber no sería la comunidad física y su memoria carnal si no el ciberespacio, la región de los mundos virtuales a través de la cual las comunidades descubren y construyen sus propios objetos, y se conocen a sí mismas como colectivos inteligentes. (...) A partir de ahora, los sistemas y los conceptos abstractos son relegados por las tarjetas de singularidades, por la descripción detallada de los grandes objetos cósmicos, de los fenómenos de la vida o de los comportamientos humanos. $\mathrm{Si}$ consideramos los grandes proyectos técnicocientíficos contemporáneos -física de partículas, astrofísica, genoma humano, espacio, nanotecnologías, vigilancia del medio ambiente y del clima- veremos que todos ellos están supeditados al ciberespacio y a sus instrumentos. Las bases de datos visuales, las simulaciones interactivas y las conferencias electrónicas garantizan un conocimiento del mundo mejor que la abstracción teórica, que ha pasado a segundo plano. O mejor dicho, definen la nueva norma del conocimiento. Además, estos instrumentos permiten una coordinación eficaz entre los productores del saber, mientras que las teorías y los sistemas suscitaban más bien la adhesión o el conflicto" (8).

Lo que plantea Lévy en esta cita genera interrogantes como los siguientes: ¿Ya no es necesaria una interpretación (conceptual) del mundo, de lo que nos rodea y de lo que se encuentra dentro de nosotros? ¿Es suficiente, para construir dicha interpretación, con experimentar, probar, implementar... sin preguntarnos por las razones para hacerlo, sin hacer explícitas las preguntas o hipótesis formuladas o las perspectivas adoptadas? ¿No sería ésta una forma de racionalidad instrumental en la que sólo importa el cómo y no el por qué o el para qué?

Sin caer en el espejismo de las explicaciones absolutas, de los métodos infalibles, de la ciencia como única forma de explicar el mundo y sus procesos; sin pretender que exista una "realidad" a partir de la cual la mente deba construir una representación "fiel", considero que nuestro conocimiento del mundo debería ser tan amplio que permita la confluencia de la abstracción y la simulación virtual como formas de experiencia; la conceptualización y el ejemplo, la descripción y la ilustración; en síntesis, la confluencia de todos los recursos del pensamiento y la expresión humanos como parte de la inteligencia colectiva. Lo demás, sería caer de nuevo en la formulación de dicotomías (pensamiento - emoción; hombre - naturaleza, sujeto - objeto, teoría - práctica). Si las teorías y los sistemas suscitan a la adhesión y al conflicto (aspecto que le preocupa a Lévy) es porque pretenden ser únicos, absolutos, totalizantes, en lugar de reconocer la diversidad, la pluralidad, la paradoja, la incertidumbre, en síntesis, la condición plena de lo humano. 
d) A propósito de las ventajas que representa el ciberespacio para la educación dice Lévy:

"Las universidades, así como las escuelas primarias y secundarias con creciente frecuencia, ofrecen a los estudiantes la posibilidad de navegar por el océano de la información y del conocimiento a través de Internet. Con el World Wide Web se pueden seguir programas educativos a distancia. Las conferencias y el correo electrónicos facilitan el asesoramiento inteligente y los mecanismos de aprendizaje cooperativo. Los hipermedios (CD-ROM, bases de datos multimedia interactivos en línea) permiten el acceso intuitivo, rápido y atractivo, a vastas fuentes de información. Con los sistemas de simulación, los aprendices pueden familiarizarse de forma práctica y económica con objetos o fenómenos complejos sin tener que exponerse a situaciones peligrosas o difíciles de controlar” (11).

Vale la pena que nos preguntemos, entonces: ¿Estamos realmente aprovechando las posibilidades que nos otorga el ciberespacio? ¿Cuáles son los usos reales que nuestros estudiantes hacen de la red? ¿Posibilitan tales usos la apropiación crítica de los conocimientos que fluyen en ella? ¿Qué orientación reciben los alumnos para lograr esto último? ¿Cómo se integra al uso de las tecnologías informáticas y del ciberespacio al desarrollo de los objetivos pedagógicos? ¿Únicamente como repositorios de información?...

Todas estas preguntas ponen en evidencia la necesidad de hacer trabajos de investigación sobre los procesos educativos donde están involucradas las tecnologías digitales. Ahora bien, ¿quiénes están llamados a hacer este trabajo que tiene implicaciones teóricas, metodológicas y políticas? ¿A partir de cuándo y con qué herramientas deben los propios estudiantes (en colegios y universidades) ocuparse de analizar lo que sucede en estos procesos educativos y comunicativos?

Sin lugar a dudas, una de las implicaciones más importantes que ha traído consigo el ciberespacio es la facilidad de acceso a la información. De ahí que para Lévy la función del profesor ya no debe ser la difundir conocimientos, pues este asunto ya está garantizado de forma más eficaz por otros medios. "El profesor se convierte en un dinamizador de la inteligencia colectiva de los grupos que están a su cargo. Su actividad se centrará en el seguimiento y la gestión del aprendizaje: estimular el intercambio de conocimientos, actuar como nexo de referencia y simbólico, dirigir de forma personalizada el proceso de aprendizaje, etc.”. (12). ¿Debemos conformarnos con que la difusión del conocimiento esté garantizada? ¿Qué hay de la apropiación de los conocimientos a los que -en principio- todos tenemos acceso? Éste es, a mi modo de ver, un asunto que merece una discusión detenida, particularmente en lo que respecta a las prácticas de lectura y escritura presentes en los procesos educativos que involucran el ciberespacio.

Una pregunta final: sabemos que es fundamental hacer una reflexión permanente sobre la incidencia del ciberespacio en la educación. Pero, ¿no sería bueno pensar, también, en la incidencia que tiene o debería tener la educación en el del ciberespacio? No olvidemos a Eco cuando nos invitaba a invertir la pregunta para que no pensáramos en los efectos de la televisión sobre las audiencias, sino en cómo "el público perjudica la televisión”. El problema de la educación en nuestros 
colegios y universidades no se resuelve mejorando la infraestructura tecnológica - comprando más y mejores aparatos-. Es necesario conocer los cambios que se dan en los procesos, las transformaciones que se presentan a nivel cognitivo (por ejemplo las tensiones que se dan entre la cibercultura y la cultura escrita), los usos no previstos de las tecnologías. El devenir del ciberespacio está haciendo posible lo que antes era impensable y ello, indudablemente, trae enormes retos para la educación.

\section{El lugar de la cultura escrita en la cibercultura}

\section{1 ¿Qué significa leer y escribir hoy?}

En el capítulo III de su libro, Pierre Lévy dedica una sección a uno de los productos más representativos del ciberespacio: el hipertexto. Este constituye el punto de partida para plantear las implicaciones que - desde mi punto de vista- trae el ciberespacio para la cultura escrita.

En términos elementales, el hipertexto es definido como un texto estructurado en red, por oposición a un texto de arquitectura lineal. "El hipertexto está constituido por nudos (elementos de información, párrafos, páginas, imágenes, secuencias musicales, etc.) y enlaces entre esos nudos, referencias, notas, punteros, 'botones' que indican mediante flechas el paso de un nudo a otro" (42).

La manera de consultar una enciclopedia (a diferencia del modo como se lee una novela ${ }^{8}$ ) o de moverse en una biblioteca ${ }^{9}$ en busca de información, se asemeja -en cierto modoal desplazamiento hipertextual realizado durante la lectura. No obstante, el soporte digital tiene dos características sui generis con respecto a los "hipertextos" anteriores a la informática: la velocidad con que se realiza la búsqueda en el índice y se ubica la información requerida; y la confluencia en el mismo medio de sonido, imagen y texto, a la que Lévy denomina multimodalidad (43). Esta descripción corresponde a un primer enfoque según el cual "el hipertexto digital se definiría como información multimodal dispuesta en red para una navegación rápida e 'intuitiva”".

Desde un segundo enfoque, complementario al anterior, "la tendencia contemporánea a la hipertextualización de los documentos puede definirse como una tendencia a la indistinción, a la mezcla de las funciones de la lectura y la escritura": El lector, en la medida en que decide qué ruta seguir, en medio de un conjunto de rutas posibles, participa en la redacción del texto que lee: "Todo ocurre como si el autor de un hipertexto constituyese una matriz de textos potenciales, siendo el papel de los navegantes el realizar algunos de estos textos haciendo jugar, cada uno a su manera, la combinatoria entre los nudos (...)” (43). “(...) los lectores pueden no sólo modificar los lazos sino también añadir o modificar nudos (textos, imágenes, etc.) conectar un hiperdocumento a otro y hacer así un solo documento de dos hipertextos separados o, según la manera de enfocar las cosas, trazar enlaces hipertextuales entre una multitud de documentos (...) Cuando el sistema de visualización en tiempo real de la estructura del hipertexto (o su cartografía dinámica) está bien concebida, o cuando la navegación puede efectuarse de manera natural e intuitiva, los hiperdocumentos abiertos accesibles para una red informática son poderosos instrumentos de escritura-lectura colectiva" (44). 
Y continúa Lévy:

"En lo que concierne al autor, hoy día constatamos que las grandes masas de informaciones recogidas por los hiperdocumentos vienen de fuentes muy diversas. La recogida y la introducción en red de estas informaciones pueden ser consideradas como una de sus 'lecturas posibles'. El autor, o más a menudo el equipo de realización, utilizan además máquinas, programas, trazos de interfaces preexistentes en la constitución de su hiperdocumento. Esto resulta de hecho, de una navegación particular entre unas informaciones, unos materiales y unos programas disponibles. El hiperdocumento editado es pues, por sí mismo, un recorrido en el seno de un hiperdocumento más vasto y vago" (44).

"La escritura y la lectura intercambian sus papeles. Quien participa en la estructuración del hipertexto, en el trazado punteado de los posibles pliegues de sentido, ya es un lector. Simétricamente, quien actualiza un recorrido, o manifiesta tal o cual aspecto de la reserva documental, contribuye a la redacción, termina momentáneamente una escritura interminable. Los recortes y los reenvíos, los cambios de sentidos originales que el lector inventa pueden ser incorporados a la estructura misma del corpus. Con el hipertexto toda lectura es una escritura potencial" (45).

Plantear que con el hipertexto se genera una indistinción entre la lectura y la escritura (el autor es un lector que recoge y organiza información de un modo hipertextual; el lector contribuye a la redacción del texto en tanto define una ruta, establece nuevos enlaces, introduce datos, etc.) es - desde mi punto de vista- la manifestación de un cambio conceptual que no debemos pasar por alto: ¿qué se entiende, a partir de los cambios suscitados en la cibercultura, por leer y escribir? Y ¿cuál es el papel de ese nuevo modo de leer y de escribir en la apropiación y producción de conocimientos? De lo dicho por Lévy se desprende que la escritura no es necesariamente un proceso de producción textual a partir de la configuración de enunciados para cumplir con una intencionalidad (afirmar, preguntar, convencer, contradecir, solicitar, etc.). Escribir es -en este nuevo contexto- el resultado de una edición de textos constituidos previamente en otros hiperdocumentos presentes en el ciberespacio.

Aunque asumamos una actitud abierta frente a los cambios, resulta inevitable preguntarse: ¿Quiénes alimentan las fuentes de información de las que se nutren aquellos que recogen y ubican informaciones en la red? ¿Quién(es) escribe(n) los “textos” de los hipertextos? ¿Dónde y cómo se forman estos productores (hiper) textuales? ¿Qué es, entonces, lo que consideramos conocimiento? ¿Quiénes son los llamados a producirlo? ¿La conceptualización está llamada a desaparecer, como de algún modo sugiere Lévy en su artículo Cibercultura y Educación? Estas preguntas resultan pertinentes si tenemos en cuenta que nuestra labor como educadores no es sólo la de orientar para la búsqueda del conocimiento y para su apropiación, sino promover la producción de conocimientos; no sólo formar lectores de hipertextos, sino agentes activos en la construcción de hiperdocumentos. 
El planteamiento de Lévy sobre esta mutación en la lectura y la escritura es un golpe fuerte para la manera como está estructurada la mente y la manera de pensar y relacionarnos con el mundo de muchos de nosotros. ¿Hacia dónde nos llevan estos cambios? ¿De qué lado nos ubicamos? ¿Qué hacer ante lo "irreversible”?"10

\subsection{El ciberespacio y los textos ¿sin contexto $?^{11}$}

En las sociedades orales, los mensajes lingüísticos [enunciados] eran recibidos en el mismo tiempo y lugar en que eran emitidos. Emisor y receptor compartían un mismo contexto [de enunciación] y un universo parecido de significación. Los actores de la comunicación estaban involucrados "en el mismo flujo vivo de interacciones"12 (86).

A partir de la invención y uso de la escritura fue posible conocer mensajes producidos por personas que se encontraban en otros lugares o en otras épocas. A partir de ese momento los actores de la comunicación no compartían necesariamente la misma situación [de enunciación] ni interactuaban de manera directa. Esto hacía necesario que los textos o mensajes escritos "subsistieran" fuera de sus condiciones de emisión y recepción, es decir, que se mantuvieran fuera de contexto. "Este 'fuera de contexto' (...) ha sido legitimado, sublimado, interiorizado por la cultura. Se convertirá en el núcleo de una determinada racionalidad y conducirá finalmente a un noción de universalidad” (87).

Como parte de lo que ello implicó, "del lado de la recepción se inventó el arte de la interpretación, de la traducción, toda una tecnología lingüística (gramáticas, diccionarios, etc.). Del lado de la emisión, se hizo un esfuerzo por componer mensajes susceptibles de circular por todos sitios, independientes de sus condiciones de producción y que contuviesen en ellos mismos, siempre que fuera posible, sus claves de interpretación o su 'razón'. A este esfuerzo práctico corresponde la idea de lo universal”: conseguir la escritura de "un tipo de mensaje autosuficiente, autoexplicativo, que contiene sus propias razones, que no serían pertinentes en una sociedad oral” (87).

Ahorabien, podemos preguntarnos si en el ciberespacio y sus escrituras es necesario utilizar estrategias textuales y discusivas para producir mensajes que puedan ser comprendidos por fuera de su contexto de enunciación. En mi concepto, la respuesta es afirmativa, pues los mensajes que circulan en la red -específicamente los textos alfabéticos- no necesariamente son leídos por sujetos que han compartido una determinada situación de enunciación y ello implica poner en práctica conocimientos procedimentales de la cultura escrita (representación de enunciadores y puntos de vista, manejo de la coherencia local y global, dominio de distintas superestructuras textuales, por mencionar sólo algunos). 
En el caso particular de la lectura, la posibilidad que brinda el ciberespacio de rebatir, complementar o comentar los textos escritos por otros en distintos contextos, en función de un proceso de comunicación interactiva, está supeditada a la comprensión que se tenga de los textos mismos. Ello no significa aspirar al "cierre semántico" como ideal de un universal totalizante, cuestionado por Pierre Levy; significa trabajar por una capacidad de leer poniendo en interrelación la organización del texto (dada por su autor) y la perspectiva del lector (Ulloa y Carvajal, 2011) y su cognición social (Van Dijk, 1996); una lectura que tenga como uno de sus propósitos identificar los distintos puntos de vista presentes en el texto leído, confrontarlos con los puntos de vista de otros enunciadores (en otros textos) y con los puntos de vista propios. Todo ello pasa por el proceso de comprensión y producción textual que requiere de una serie de conocimientos procedimentales, de un "saber hacer", propio de la cultura escrita y de sus cánones, configurados históricamente (Ulloa y Carvajal, 2006).

4. Los retos del ciberespacio: el lugar de la cultura escrita y de la educación

Tomando como referencia lo expuesto por Pierre Lévy, encuentro varios desafíos tanto para la cultura escrita como para la educación, a partir de la presencia de ambas en el ciberespacio.

a. La circulación de textos que no han pasado por un filtro (v.g. editores, redactores, comités científicos) tiene por lo menos, dos consecuencias: En primer lugar, ante la posibilidad que tienen todas las personas o grupos sociales de dar a conocer nuevas ideas y experiencias, sin contar para ello con el aval de los especialistas reconocidos (comités de las revistas científicas), el sistema de regulación de la ciencia está permanentemente puesto en cuestión. En segundo lugar, los individuos pueden acceder a las "fuentes vivas del saber" y articularse a comunidades virtuales dedicadas al aprendizaje cooperativo, sin necesidad de autorización alguna, al margen de los constreñimientos de las instituciones formales educativas.

Desde mi punto de vista, el dominio de la cultura escrita (tal y como ha sido definida en el presente artículo) es, en este contexto, un factor decisivo. Saber leer (actividad que trasciende el dominio del código alfabético) permite tener criterios de selección de textos, establecer relaciones inter textuales, reconocer diferentes puntos de vista presentes en los textos y confrontarlos entre sí y con el punto de vista propio. De igual modo, producir textos que 
puedan ser comprendidos por otros permite compartir esas elaboraciones personales y ponerlas en discusión. El aprendizaje cooperativo exige también unos mínimos insumos en lo que respecta a los conocimientos procedimentales de la cultura escrita (Ulloa y Carvajal, 2006).

La cuestión sería, entonces, encontrar salidas a la relación paradójica que la cultura escrita tiene con la cibercultura y que describo a continuación.

Por un lado, encontramos la emergencia de formas de escritura no canónicas -o que responden a cánones emergentes-, el "predominio" de la imagen sobre el texto, la proximidad con la oralidad - expresada en la dependencia del contexto de enunciacióny, en términos globales, la debilitación de la relación de los sujetos- especial aunque no necesariamente de los niños y jóvenes- con la cultura escrita. Por otro lado, encontramos la afluencia de textos de toda índole, la cual que exige un dominio del canon de la cultura escrita que permita la apropiación de conocimientos y la producción de nuevos conocimientos, por lo menos en lo que respecta a los textos alfabéticos que se encuentran en el ciberespacio. Nunca antes los cánones de la cultura escrita habían estado en una situación de aparente vulnerabilidad (por lo menos eso es lo que parece estar sucediendo), pero nunca antes habíamos tenido la posibilidad de acceder a tantos textos escritos producidos en distintos lugares del mundo y en distintas épocas.

Tal vez la sensación de pérdida (uno de los imaginarios que circulan en torno a las tecnologías digitales) se derive de que la escritura y la lectura deben compartir un espacio que era sólo suyo (el de la cultura del impreso) con otras formas de expresión "multimodales" en el contexto del ciberespacio. Es normal que ello genere tensiones, conflictos, angustias; pero esto no nos puede llevar a la inmovilidad.

b. Formas de exclusión en la cibercultura

Como lo plantea Lévy, "todo sistema de comunicación fabrica sus excluidos" y, de manera más general, "cada universal produce sus excluidos (...) Lo universal sin totalidad [inaugurado por la cibercultura] no escapa a la regla de exclusión”. En la cibercultura, estar desconectado significa estar excluido, es decir, no participar "de la densidad relacional y cognitiva de las comunidades virtuales y de la inteligencia colectiva" (212). En lo que respecta a la cultura escrita en las sociedades occidentales, está excluido quien no domina los cánones de la lectura y la escritura alfabética. Si tenemos en cuenta que en la sociedad coexisten -bien sea de manera conflictiva o complementaria- la cultura escrita y la tecnocultura, es pertinente analizar el tipo de exclusiones que de esa coexistencia se pueden derivar.

Si la participación en la cibercultura tiene una dimensión cognitiva, como el mismo Pierre Lévy lo reconoce, la no participación en la cultura escrita (en tanto mediación cognitiva) representaría una forma de exclusión que no se suple por la interconexión. En el caso particular de la sociedad colombiana, existe la posibilidad de una doble exclusión, representada en la escasa o nula adscripción a la cultura escrita y en la falta de apropiación de la cibercultura particularmente en sectores vulnerables de la población.

Cuando la relación con la cultura escrita es muy precaria, es posible que ello limite la participación activa y productiva en la cibercultura. Esto puede suceder en el caso específico de las comunidades virtuales cuyas redes se alimentan de la lectura y la producción de textos alfabéticos. En otras palabras, para cierto tipo de interacciones y construcciones cooperativas, no es suficiente con la interconexión y el dominio de 
los conocimientos procedimentales (el "saber hacer") de la cibercultura. Es necesario, también, el dominio -en un cierto grado- de la cultura escrita con los conocimientos semánticos y procedimentales que le son propios.

El mismo Lévy lo reconoce cuando dice:

"El problema del 'acceso para todos' no puede reducirse a las dimensiones tecnológicas y financiera, como algunos opinan habitualmente. No basta con encontrarse delante de una pantalla dotada de todas las interfaces asequibles que se quiera para vencer una situación de inferioridad. Hay que estar, sobre todo, en condiciones de participar activamente en los procesos de inteligencia colectiva que representan el principal interés del ciberespacio" (212).

Por eso, sostengo que el papel que juega la educación es crucial, en un doble sentido: como espacio que favorezca la relación con la cultura escrita y sus cánones, y como espacio que enriquezca y complejice los usos de las tecnologías; usos que traspasen las formas de sociabilidad informales (como sucede en el chat, en la mensajería instantánea o en algunas redes sociales) y promuevan el enriquecimiento de la inteligencia colectiva como proyecto social y cultural de largo alcance.

Una de las manifestaciones de la inteligencia colectiva es la producción y lectura de textos. La construcción y fortalecimiento de las comunidades virtuales pasa en gran medida por el texto alfabético y, en ese sentido, gran parte de sus alcances está determinado por la cultura escrita. Escritura y lectura son formas en que se expresa y se concreta la interconectividad e interactividad en el ciberespacio. Por supuesto, sin asumir la lectura y la escritura como instrumentos para una visión totalizadora, sino como prácticas comunicativas que promuevan y alimenten la inteligencia colectiva.

c. El ciberespacio, sinónimo de caos y confusión

Como ya se dijo, en el ciberespacio los distintos usuarios pueden alimentar la red sin ningún tipo de restricción, sin intermediarios ni censuras institucionales o estatales. Como consecuencia de ello, no hay una instancia que garantice la validez de los datos disponibles. Lévy se pregunta por el grado de credibilidad y confianza que podemos dar a las informaciones proporcionadas por el ciberespacio: ¿No estamos asistiendo "simplemente a una disolución cultural más bien que a un progreso, disolución que no puede servir, en último término más que para aquellos que ya tienen un punto de referencia, es decir, las personas privilegiadas por su educación, su medio, sus redes intelectuales privadas?" (218).

Aunque las califica de legítimas, Lévy plantea que estas preguntas parten de premisas falsas, pues: (a) Las páginas web dependen de instituciones reconocidas o son producidas por personas que firman sus contribuciones y argumentan la validez de sus planteamientos ante la comunidad de cibernautas. (b) En internet opera una especie de opinión pública. Las revistas, catálogos e índices en línea citan como ejemplos los mejores sitios; no es común que los cibernautas sean arrastrados a sitios de dudosa validez. 
En cuanto al caos que tiende a desfavorecer a los que no cuentan con referencias personales o sociales sólidas, dice que se trata de un temor fundado sólo en parte: las personas o colectivos pueden orientar y ordenar por su cuenta jerarquías, selecciones y estructuras. Lo que definitivamente ha desaparecido, son "las selecciones, las jerarquías o las estructuras de conocimientos pretendidamente válidas para todos y en todo tiempo, a saber, el universal totalizante”. Para él, existen posibilidades técnicas que permiten dar un orden local y provisional al gran desorden global. "Además, no hay que representarse el ciberespacio poblado de individuos aislados y perdidos entre masas de informaciones. La red es, primero, un instrumento de comunicación entre individuos, un lugar virtual donde comunidades ayudan a sus miembros a aprender lo que quieren saber. Los datos no representan más que la materia prima de un proceso intelectual y social vivo y altamente elaborado. Finalmente, toda la inteligencia colectiva del mundo no dispensará jamás de inteligencia personal, del esfuerzo individual y del tiempo necesario para aprender, para buscar, para evaluar, para integrarse en diversas comunidades, aunque sean virtuales. La red no pensará nunca en nuestro lugar, y tanto mejor así” (220).

\section{Síntesis: Ciberespacio y cibercultura desde la perspectiva de Pierre Lévy}

Para hacer una síntesis del planteamiento de Pierre Lévy, mencionaré los rasgos que caracterizan el ciberespacio (los cuales se relacionan entre sí de manera recíproca) y los valores que encarna la cibercultura. Posteriormente reiteraré -empleando un conjunto de citas textuales- las que pueden considerarse sus tesis centrales.

a) Los rasgos que caracterizan el ciberespacio son:

Interconectividad (o conectividad global)

Accesibilidad a distancia, que conlleva a la universalidad

Interacción: el ciberespacio es dispositivo de comunicación

interactivo y comunitario

Desterritorialización

Digitalización

Virtualización

Procesos de simulación

Velocidad en los procesos y en los cambios que genera el

ciberespacio

Hipertextualización

Posibilidad de configuración de una memoria colectiva que

resulta de la comunicación ininterrumpida, propia del dispositivo

comunicacional todos-todos

Sinergia

Multimedialidad

Desarrollo de comunidades virtuales

Tendencia a la universalidad, expresada en la ausencia de un orden predeterminado y de un centro; resultado de la suma de la interconectividad y la digitalización Inteligencia colectiva, finalidad última y perspectiva espiritual de la cibercultura 
b) Los valores que encarna la cibercultura son:

La información: lo que contiene y trasporta el ciberespacio;

aquello que producen y a lo que acceden los usuarios del

ciberespacio.

La autonomía.

La interconexión generalizada como utopía, que emerge como

nueva forma de lo universal.

La inteligencia colectiva, uno de los principios y motores de la

cibercultura.

Lo universal sin totalidad, significación última de la red.

c) Las tesis que Pierre Lévy desarrolla en torno al ciberespacio y la cibercultura están construidas alrededor de tres ejes:

Las transformaciones en la relación con el conocimiento

"El uso creciente de tecnologías numéricas y de redes de comunicación interactiva acompaña y acentúa el cambio profundo de la relación con el conocimiento (...). Las tecnologías intelectuales con soporte numérico prolongan ciertas capacidades cognitivas del ser humano (memoria, imaginación, percepción)". Esto trae como consecuencia “una nueva definición de su alcance, su significación e incluso, a veces, de su naturaleza”. La cibernética hace posible la creación colectiva distribuida, el aprendizaje cooperativo y la colaboración en red. Como consecuencia de ello, se pone en cuestión "el funcionamiento de las instituciones y las formas habituales de división del trabajo, tanto en la empresa como en la escuela" (15-16).

Los modos de relación promovidos el ciberespacio

Las mutaciones culturales que resultan del advenimiento del ciberespacio (las mutaciones de la cibercultura) no se encuentran en la posibilidad de mezclar el texto, la imagen y el sonido (que corresponden a tipos de representaciones y a sus determinadas modalidades perceptivas), sino en los nuevos dispositivos informacionales (mundos virtuales, información en flujo) y comunicacionales (comunicación todos-todos) (49). En ese sentido, lo relevante no es el surgimiento de un nuevo media (el "multimedia") sino los dispositivos informacionales (en red, en flujo, en mundos virtuales) y el dispositivo de comunicación interactivo y comunitario, que constituyen una novedad al representar "un modo de relación entre personas, en una cierta calidad de lazo social” (52).

La desarticulación de la dupla universalidad-totalidad y el surgimiento de un universal no totalizante

"El mayor acontecimiento cultural anunciado por la emergencia del ciberespacio es el desembrague entre esos dos operadores sociales o máquinas abstractas (¡mucho más que conceptos!) que son la universalidad y la totalidad. La causa es simple: el ciberespacio disuelve la pragmática de comunicación que, desde el invento de la escritura, había 
unido a lo universal y a la totalidad. Nos devuelve, en efecto, a la situación anterior a la escritura - pero a otra escala y en otra órbita - en la medida en que la interconexión y el dinamismo en tiempo real de las memorias en línea hacen de nuevo compartir el mismo contexto, el mismo inmenso hipertexto vivo, con los interlocutores de la comunicación" (91).

"Lejos de ser una subcultura de los fanáticos de la red, la cibercultura expresa una mutación mayor de la esencia misma de la cultura. Según la tesis que he desarrollado en este informe, la clave de la cultura del futuro es el concepto de universal sin totalidad. En esta proposición, lo 'universal' significa la presencia virtual de la humanidad por sí misma. Lo universal cobija aquí el aquí y ahora de la especie, su punto de encuentro, un aquí y ahora paradójico, sin lugar ni tiempo claramente asignables” (223). “(...) la cibercultura inventa otra manera de hacer llegar la presencia virtual al seno mismo de la humanidad, distinta de la imposición de una unidad de sentido" (224).

6. La cultura escrita en el ciberespacio: preguntas para una carta de navegación

A lo largo de este artículo he planteado una serie de preguntas y reflexiones derivadas de la lectura del libro de Pierre Lévy Cibercultura. La cultura de la sociedad digital.

Retomo algunas de ellas, o las formulo de un modo más general, para cerrar:

e) Si tenemos en cuenta que la llegada de un nuevo dispositivo tecnológico genera transformaciones en los dispositivos preexistentes, ¿qué consecuencias trae para la escritura el auge de la cibercultura? La lectura y la escritura no desaparecerán, pero sí se trasformarán... ¿De qué manera? ¿Qué indicios tenemos de estos cambios? ¿Qué pasará con las formas de escritura pasadas y presentes?

f) Contrario a lo que se asume de manera desprevenida, el ciberespacio demanda más tiempo para poder cubrir los extensos espacios de información. ¿Cómo están asumiendo nuestros estudiantes (niños y jóvenes) esta situación, teniendo en cuenta que con un solo click parecerían estar resueltas sus necesidades de búsqueda de información? ¿Tienen ellos claro que una cosa es el acceso y otra el procesamiento de la información y la apropiación de los conocimientos? ¿Saben ellos que éstos dos últimos propósitos demandan de un tiempo y esfuerzo considerable; que si queremos pescar, además de navegar y surfear debemos tener capacidad de orientación en mar abierto, saber tirar el ancla y la red en el sitio adecuado, reconocer islas perdidas y acercarnos a ellas sin encallar, sobrevivir en terrenos inhóspitos? 
g) ¿Qué significa adscribirse a la cultura escrita en los tiempos de la informática? Qué significa, para lograr dicha adscripción, tener un dominio o, por el contrario, una escasa relación con la cultura escrita?

h) Afirma Levy que el ciberespacio "se erige en sistema de sistemas pero, por este mismo hecho, es también el sistema del caos (...) [pues] por su irreprimible profusión, [acoge] todas las opacidades del sentido (...)" (84). Esto nos lleva a preguntarnos ¿qué significa leer y escribir en el ciberespacio? $¿$ Ante las exigencias que nos hace el ciberespacio, podemos prescindir de la adscripción a la cultura escrita y sus cánones? ¿No está anunciando Pierre Lévy, de algún modo, la desaparición del canon de la escritura, por innecesario? ¿Todo en el ciberespacio queda reducido a la conectividad y a la interactividad? ¿No requieren algunas formas de interactividad (por ejemplo las comunidades virtuales) el dominio de la palabra escrita como forma de comunicación?

i) El ciberespacio está sin duda, plagado de oportunidades y posibilidades. Pero, además de la conectividad (que se da por existente), ¿qué se requiere para que podamos aprovecharlas?

Estas preguntas y otras que han sido formuladas al lo largo del artículo son una muestra de la riqueza investigativa que se despliega ante nuestros ojos. Quienes estamos interesados en la investigación de los procesos educativos no hubiéramos podido nacer en mejor época. ¡Buen tiempo y buena mar! 
1. Comunicadora Social de la Universidad del Valle, Licenciada en Música, Magíster en Comunicación y Diseño Cultural de la misma universidad. Actualmente realiza el segundo año del Doctorado en Ciencias de la Educación, Área Pensamiento Educativo y Comunicación, de RUDECOLOMBIA, Universidad Tecnológica de Pereira. Email: giovanacarv@hotmail.com.

2. Estos objetivos están articulados a la formulación de la pregunta de investigación en el proyecto de tesis doctoral denominado "La cultura escrita en el ciberespacio: ¿Nuevos conceptos, nuevas prácticas?”. Doctorado en Ciencias de la Educación, Área Pensamiento Educativo y Comunicación, RUDECOLOMBIA, Universidad Tecnológica de Pereira.

3. Salvo cuando se especifique lo contrario, la paginación corresponde al libro Cibercultura. La cultura de la sociedad digital. Las cursivas que aparecen en algunas citas textuales son originales del autor. Los subrayados son míos.

4. En esta parte de su libro, Pierre Lévy presenta una serie de conceptos que le permitirán precisar lo que significa la multimedia: media (medios de comunicación), soporte o vehículo del mensaje; modalidades perceptivas puestas en juego en la recepción de un mensaje (vg. vista, oído, tacto); tipos de representaciones (texto, imagen, música); codificación, es decir, el sistema de grabación o transmisión de las informaciones (analógica o digital); dispositivo informacional, que "califica la estructura del mensaje o el modo de relación de los elementos de información” (lineal o en red); dispositivo comunicacional que alude al tipo de relación que se establece entre los participantes de la comunicación (uno-todos: "un centro emisor envía sus mensajes a un gran número de receptores pasivos y dispersos" (prensa, radio, televisión); uno-uno: "organizan relaciones recíprocas entre interlocutores pero solamente según contactos de individuo a individuo o de punto a punto" (correo, teléfono); todos-todos) (47 a 49).

5. Lévy no habla explícitamente del canon de la cultura escrita alfabética, pero se refiere - efectivamente- a lo éste representa en la cultura occidental (Ulloa y Carvajal, 2006). 
6. Para esta parte del artículo, retomaré apartes del texto titulado "Cibercultura y Educación” (Lévy, 1999), cuyo contenido corresponde a los capítulos X y XI del libro, titulados "La nueva relación con el saber" y "Las mutaciones de la educación", respectivamente. Las citaciones corresponden al artículo publicado en 1999.

7. Según Ulloa y Carvajal (2006), la cultura escrita se refiere tanto a la lectura y a la escritura, como a las relaciones entre éstas y el conocimiento. Leer y escribir, como prácticas de la cultura escrita, involucran complejos procesos mentales que implican el uso de distintos recursos -técnicos, informativos, lingüísticos, discursivos, cognitivos- y su aprovechamiento para analizar, interpretar, cuestionar o transformar los textos existentes y para crear nuevos textos. Además de un saber declarativo -un saber qué-, la cultura escrita alfabética comprende un sistema de conocimientos modales o procedimentales -un saber cómo, un saber hacer- (Serrano, 2000; De Torres et al, 1999) relacionados con el leer y escribir, en tanto saberes específicos cuya práctica, ejercida por grupos y comunidades, ha incidido significativamente en los cambios socioculturales del mundo occidental. Los conocimientos procedimentales implicados en la lectura y la escritura permiten acceder a otros conocimientos semánticos y procedimentales, característicos de las distintas prácticas sociales, entre ellas las científicas y las educativas. Por ello, la cultura escrita constituye una mediación cognitiva (un conocimiento que permite la adquisición y apropiación de otros conocimientos) en los procesos de enseñanza aprendizaje dentro o fuera del mundo escolar.

La cultura escrita alfabética configuró unas formas de construcción y organización textual, en función de un lector imaginado y ausente. A esas maneras de escribir les corresponde un modo de leer determinado por la estructuración de lo escrito dada por un autor y las marcas verbales que éste le ofrece al lector para orientarlo en la comprensión, en el modo como debe tomar los enunciados (v.g. si en su sentido literal o metafórico; si como afirmación o como ironía; si como realidad o como posibilidad; si como pregunta o como duda; si como cita textual o como paráfrasis...). Los recursos lingüísticos, discursivos y cognitivos que hacen parte de los cánones construidos históricamente por la cultura escrita alfabética están asociados a procesos de pensamiento que se fueron consolidando, durante los últimos cinco siglos, dando lugar a modos de leer específicos, que reconocen la perspectiva de la organización del texto (sus marcas, sus indicios) y no sólo la perspectiva del lector y su cognición social (T. Van Dijk, 1994). En otras palabras, esos modos de leer y de escribir corresponden a saberes procedimentales que junto con los saberes enciclopédicos configuran la noción de cultura escrita propuesta por Ulloa y Carvajal, diferente a la noción tradicional de "cultura letrada" o "enciclopédica".

${ }^{8 .}$ Valgan excepciones como la de Rayuela, la novela de Julio Cortázar.

9. Para Lévy, siempre que se conserve la definición de 'texto en red' o de red documental, una biblioteca puede ser considerada como un hipertexto (43).

10. No quiero cerrar esta sección sin recordar que el papel del lector en la producción del texto ha sido trabajado por distintos autores, entre ellos Roland Barthes (1984). En el capítulo titulado "Escribir la lectura", Barthes señalaba que cuando levantamos nuestra cabeza (no por desinterés, sino "a causa de la gran afluencia de ideas, de excitaciones, de asociaciones” que el texto produce en nosotros) estamos escribiendo un texto que él denomina "texto-lectura" (p. 35). Otros autores que han trabajado el tema son Umberto Eco (1981) y Wolfang Iser (1987). Una síntesis de sus planteamientos y de la relación entre ellos se presenta en G. Carvajal (2011).

11. Retomo aquí apartes del libro en el que Lévy hace referencia a la transformación en la "ecología de los medios de comunicación" para desarrollar su idea de "sentido de lo universal no totalizante", mencionado en una parte previa de este artículo.

12. Aunque prefiero emplear las categorías enunciador y enunciatario en un determinado contexto de enunciación, donde se producen e intercambian enunciados, conservo los términos mensaje, emisor y receptor, que son los empleados por Lévy en su libro. 


\section{Referencias}

Barthes, Roland (1984). El Susurro del Lenguaje. Más allá de la palabra y la escritura, Ediciones Paidós Ibérica, Barcelona.

Carvajal, Giovanna (2011). Del consumo de bienes materiales a la interacción texto-lector, Revista Nexus, No. 9, Universidad del Valle.

De Torres, Julio Santiago, et al. (1999). Procesos Psicológicos Básicos, Editorial Mc Graw Hill, Madrid.

Eco, Umberto (1981). Lector in Fabula, Editorial Lumen, Barcelona.

Iser, Wolfang (1987). El acto de leer, Taurus, Madrid.

Lévy, Pierre (1999). Cibercultura y educación, en La Universidad en la Sociedad de la Información, Documentos Columbus sobre gestión universitaria (Documento en versión digital).

(2007). Cibercultura. La cultura de la sociedad digital, Antropos, Barcelona.

Ulloa, Alejandro, Carvajal, Giovanna (2006). Cultura escrita, conocimiento y tecnocultura. El marco teórico de una investigación exploratoria en la Universidad del Valle, Revista Nexus, No. 2, Escuela de Comunicación Social.

(2011). Cultura escrita y tecnocultura contemporánea: mediaciones cognitivas en la formación universitaria, en: Revista Nexus, No. 10, Escuela de Comunicación Social de la Universidad del Valle.

Van Dijk, Teun (1996). La Ciencia del Texto, Editorial Paidós, Barcelona.

Serrano, Eduardo (2000). Consideraciones Semióticas sobre el Concepto de Competencia, en El Concepto de Competencia: Una mirada interdisciplinar, Volumen I (pp.179-200), Alejandría Libros, Bogotá.

Recibido: septiembre 30 de 2012 / Aprobado: noviembre 30 